\title{
Change of Plasma Chemistry Values in Captive Breeding Loggerhead Turtles (Caretta caretta)
}

\author{
Yuka Kakizoe, Ken Sakaoka, Yuichiro Akune, Yoshihiko Kanou, \\ Tomomi Saito, and Itaru Uchida
}

Port of Nagoya Public Aquarium, 1-3, Minato-Machi, Minato-ku, Nagoya, Aichi 455-0033, Japan

Correspondence should be addressed to Yuka Kakizoe; yu-kakizoe@nagoyaminato.or.jp

Received 7 March 2013; Accepted 1 April 2013

Academic Editors: R. Castiglia, L. Kaczmarek, I. Krams, and B. A. Young

Copyright (C) 2013 Yuka Kakizoe et al. This is an open access article distributed under the Creative Commons Attribution License, which permits unrestricted use, distribution, and reproduction in any medium, provided the original work is properly cited.

\begin{abstract}
Loggerhead turtles, Caretta caretta, have been laying eggs in an indoor artificial beach since 1995, at the Port of Nagoya Public Aquarium (PNPA). Two males and four females were mated and those four landed and laid eggs several times during the breeding period in 1996. In 1998 egg laying was observed from April to July and mating was one or two months prior to the nesting season. Blood samples from these individuals were collected monthly in the previously mentioned years in order to investigate the changes in sex steroid hormones (testosterone, estradiol, and progesterone). Moreover, blood chemistry values (total protein, albumin, triglyceride, total cholesterol, total calcium, and inorganic phosphorus) were investigated. In 1998, for the two males, changes in testosterone levels were additionally examined. Blood chemistry values of each turtle changed periodically as sex steroids did based on the breeding period and laying cycle. Data from a completely artificial environment such as the one at the PNPA provide elucidation of the reproductive physiology in these endangered species.
\end{abstract}

\section{Introduction}

Designated as an endangered species and listed in the CITES (Convention on International Trade in Endangered Species of Wild Fauna and Flora) Appendices I, conservation of sea turtles has been actively conducted. However, wild population has been decreased due to the loss of egg-laying sites, fisheries bycatch, and the demand for their eggs as food. Sea turtles are common animals for exhibition in aquariums; however, their successful breeding in an artificial environment is only observed in Port of Nagoya Public Aquarium (PNPA) [1]. For the recovery of the stock of sea turtles, captive breeding should be stepped up as well as habitat conservation, and the returning of captive bred individuals to wild environment should be implemented actively. For the successive breeding of sea turtles in an artificial environment, the understanding of reproductive physiology and the establishment of blood characteristics for their health management are absolutely imperative.

Since 1995, mainly the loggerhead turtles, C. caretta, have been landing and laying eggs every year, resulting in the first successful breeding in this species in an artificial environment. In PNPA, the studies for understanding reproductive physiology and ecology and the establishment of blood standard values have been continued by using those reproductive individuals. This study reports the transition of blood chemistry values (total protein (TP), albumin (ALB), triglyceride (TG), total cholesterol (TCHO), total calcium $(\mathrm{Ca})$, inorganic phosphorus $(\mathrm{P})$, and testosterone) of mature individuals, which is indispensable for proper breeding and health control in reproductive physiology.

\section{Materials and Methods}

2.1. Rearing and Breeding Facility. The breeding tank is doughnut shaped and contains a total water volume of $560 \mathrm{~m}^{3}$. The outer diameter is $13 \mathrm{~m}$ and the inner is $4 \mathrm{~m}$. The depth is $2.5 \mathrm{~m}$. Adjacent to the tank is an artificial beach measuring $5 \mathrm{~m}$ in width and $20 \mathrm{~m}$ in length, with sand depth of about $1.5 \mathrm{~m}$. For lighting, nine $400 \mathrm{w}$ metal halide lamps were used. Lighting hours followed the opening hours of the aquarium. The tank was also structured to let natural light in through glass windows in the ceiling. The minimum 
TABLE 1: Individual data of breeding loggerhead turtles.

\begin{tabular}{|c|c|c|c|c|c|}
\hline Identifying number & Sex & Captured date from the wild & Carapace length $(\mathrm{cm})^{*}$ & Body weight $(\mathrm{kg})^{*}$ & Nesting times \\
\hline Cc- 01 & $\mathrm{~F}$ & 6/14/1991 & 79.6 & 88.3 & 4 \\
\hline Cc-04 & $\mathrm{F}$ & 6/19/1991 & 85.1 & 94.8 & 5 \\
\hline Cc-06 & $\mathrm{F}$ & $6 / 21 / 1991$ & N.D. ${ }^{* *}$ & 79.3 & 1 \\
\hline Cc-11 & $\mathrm{F}$ & $7 / 16 / 1992$ & 79.0 & 85.3 & 5 \\
\hline Cc- 07 & M & 7/9/1991 & 90.8 & 115.9 & \\
\hline Cc-14 & M & $4 / 2 / 1993$ & 79.6 & 81.4 & \\
\hline
\end{tabular}

* Measurement was conducted on January 1996 for females, January 1994 for males.

** No data.

water temperature in the tank was set at $23^{\circ} \mathrm{C}$ in February and gradually rose towards $26^{\circ} \mathrm{C}$ by April. The highest water temperature was set at $27^{\circ} \mathrm{C}$ in July and was gradually lowered to $25^{\circ} \mathrm{C}$ by December.

The turtles were fed mainly on fish, squid, shrimp, and clam, together with Chinese cabbage, and seaweed, three times a week. In addition, the amounts of calcium and phosphorus contained in food were examined, and calcium preparation (Wada Calcium pharmaceutical Co. Ltd. 2-736, Imazuminami, Tsurumi-ku, Osaka 5380043, Japan) was added so that their proportion was one to one.

The average feeding amount per year was $0.5 \%$ of body weight. The volume was fluctuated seasonally $(0.0-0.8 \%)$. Before and during the breeding period, appetite of all turtles decreased.

2.2. Blood Sampling and Measurement Items. In 1996, blood sampling was conducted periodically (monthly, at the time of each egg laying and on the seventh day after each egg laying) on the nesting sea turtles. In 1998, blood of two mating males was sampled monthly for investigation of annual changes in each blood chemistry value (Table 1).

Blood was collected from the dorsal cervical venous sinus by $18 \mathrm{G}$ needle and a $10 \mathrm{~mL}$ syringe (Terumo Corporation 441, 2-chome, Hatagaya, Shibuya-ku, Tokyo 1510072, Japan) that are heparin-treated for anticoagulation. Blood was sampled at 10 a.m. \pm 1 hour, and then it was immediately centrifuged to separate plasma.

The plasma chemistry values of total protein (TP), albumin (ALB), total calcium (Ca), inorganic phosphorus $(\mathrm{P})$, triglyceride $(\mathrm{TG})$, and total cholesterol $(\mathrm{TCHO})$ were immediately examined.

Fuji Drychem-3000 (Fuji Medical Systems, Co. Ltd. 226-30, Nishiazabu, Minato-ku, Tokyo 1060031, Japan) was performed for each analysis. The colorimetric method was used to measure. The other plasma was frozen, kept at $-20^{\circ} \mathrm{C}$, and submitted to a public human laboratory (Nagoya Rinsho Kensa Center 3-2, Takiko dori, Showa-ku, Nagoya, Aichi, 4660055, Japan) to measure male's testosterone concentration. The used measuring method was radioimmunoassay (RIA).

All data were compared using the Friedman test and examined for seasonal changes.

\section{Results}

Table 1 shows the individual data of sea turtles. The results were based on the data from the nesting four turtles during 1996 and two males which mated four females in 1996 and 1998. In 1998, egg laying was observed from April to July and mating was observed one or two months before nesting season.

\subsection{Annual Examination}

3.1.1. Testosterone. Monthly change in the concentration of testosterone of two male loggerhead turtles is shown in Figure 1. The concentration of testosterone showed high values from January to April and reached the highest in March and April (72.4 ng/mL (Cc-07), $135.0 \mathrm{ng} / \mathrm{mL}$ (Cc14), resp.). During the nesting period, the concentration decreased gradually. After that, the concentration had a tendency to stabilize for 2-3 months and then rose again.

3.1.2. Blood Protein. TP of males showed almost constant values throughout a year. Cc-07 and Cc-14 indicated $5.6 \pm$ 0.4 and $4.7 \pm 0.7 \mathrm{~g} / \mathrm{dl}$, respectively. Male's ALB also showed constant values. Cc-07 and Cc-14 indicated $2.2 \pm 0.1$ and $1.8 \pm$ $0.2 \mathrm{~g} / \mathrm{dl}$, respectively.

TP and ALB of females indicated high values from winter to spring; then they were decreased seasonally $(P<0.01)$. TP reached the highest value in March $(8.5 \pm 1.5 \mathrm{~g} / \mathrm{d})$ and after that decreased gradually during the nesting period. It indicated the lowest value in September $(4.0 \pm 0.5 \mathrm{~g} / \mathrm{dl})$. ALB showed the highest value in January $(2.5 \pm 0.2 \mathrm{~g} / \mathrm{dl})$, and the lowest value in September $(1.6 \pm 0.2 \mathrm{~g} / \mathrm{dl})$. During several months after the end of nesting period, TP and ALB maintained the low levels. Then, they increased after autumn.

3.1.3. Blood Lipid. TG of males showed trimodal distribution. The peaks were shown at the winter, summer, and late autumn (Figure 2). TCHO indicated individual differences. TCHO of Cc-07 maintained the high level from winter to after nesting period $(412.0 \pm 39.1 \mathrm{mg} / \mathrm{dl})$ while that of Cc-14 decreased during summer and is kept to that $(220.5 \pm 63.1 \mathrm{mg} / \mathrm{dl})$.

Lipid of females indicated seasonal changes $(P<0.01)$ in the same way as protein and TG increased from winter to the beginning of nesting period. Then it showed the highest value 


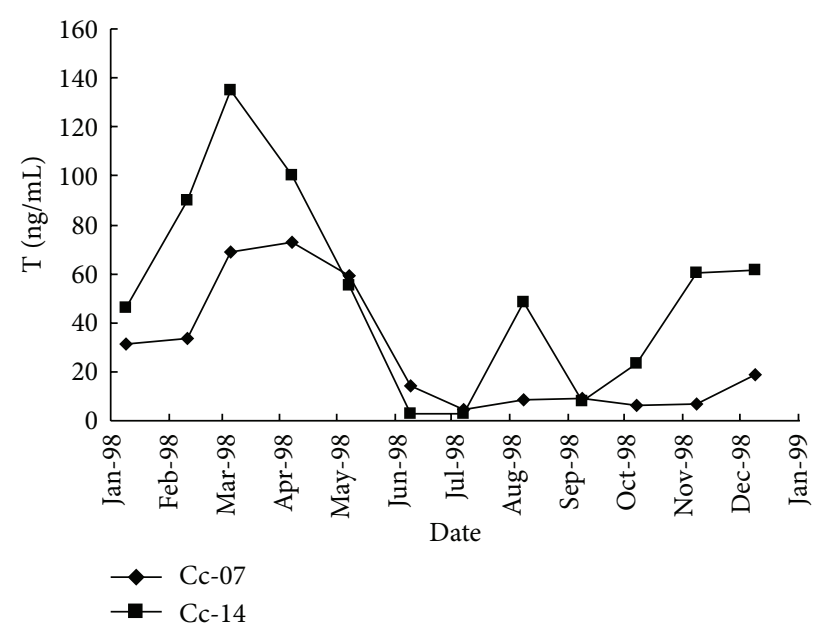

FIgURE 1: Change in plasma $\mathrm{T}$ concentration of breeding male loggerhead turtles (Cc-07 and Cc-14).

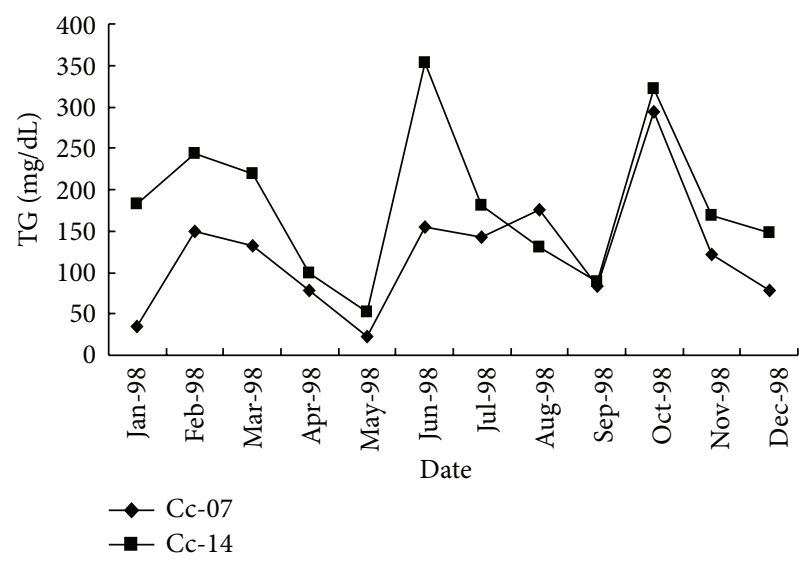

FIgUre 2: Change in plasma TG concentration of breeding male loggerhead turtles (Cc-07 and Cc-14).

in March $(1768.0 \pm 530.13 \mathrm{mg} / \mathrm{dl})$. After that, it decreased rapidly during the nesting period. It showed constant low value, and then it increased from winter (Figure 3 ).

About TCHO, it significantly increased from winter to summer $(P<0.01)$ and it decreased significantly $(P<$ 0.01 ), after autumn. This transition shows almost identical pattern among individuals, but there was the concentration difference individually. TCHO of Cc-11 indicated remarkably high value in comparison to the other 3 turtles (Cc-01, 04, and 06) (Figure 4).

3.1.4. Blood Electrolytes. Ca of males showed constant values throughout a year. Cc-07 and Cc-14 indicated $8.4 \pm 0.7$ and $7.5 \pm 0.9 \mathrm{mg} / \mathrm{dl}$, respectively. $\mathrm{P}$ of males also showed constant values. Cc- 07 and Cc-14 indicated $5.8 \pm 0.4$ and 5.1 $\pm 0.7 \mathrm{mg} / \mathrm{dl}$, respectively.

$\mathrm{Ca}$ of females decreased gradually and significantly from winter to autumn $(P<0.01$ Junuary: $14.0 \pm 0.4 \mathrm{mg} / \mathrm{dl}$, Sep: 8.0 $\pm 0.5 \mathrm{mg} / \mathrm{dl}$ ) and then increased after autumn (Figure 5). P of females showed constant values throughout a year (Figure 6).

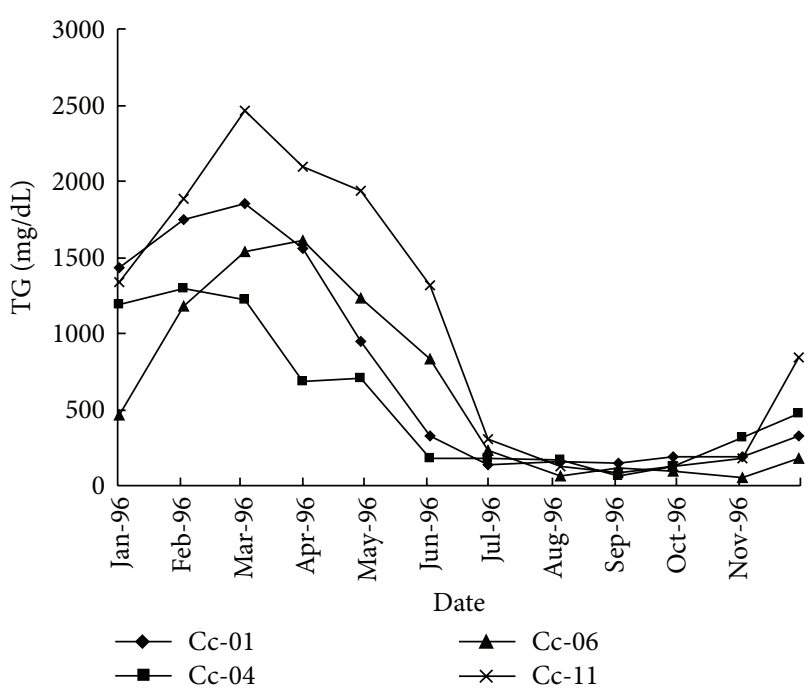

FIGURE 3: Change in plasma TG concentration of breeding female loggerhead turtles (Cc-01, Cc-04, Cc-06, and Cc-11).

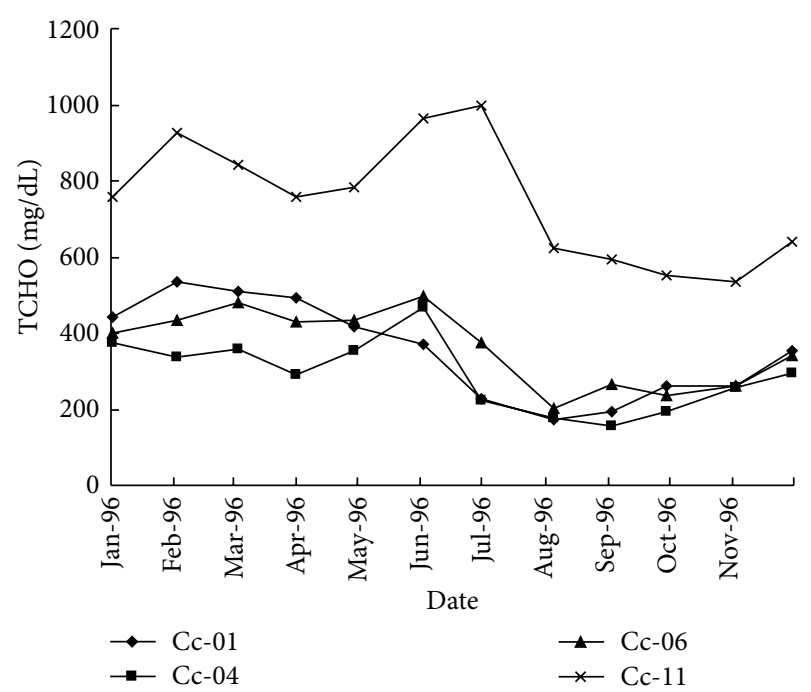

Figure 4: Change in plasma TCHO concentration of breeding female loggerhead turtles (Cc-01, Cc-04, Cc-06, and Cc-11).

The ratio of $\mathrm{Ca} / \mathrm{P}$ indicated significantly low value during summer in females $(P<0.05$, Figure 7$)$.

3.2. Nesting Season Examination. From this section on, the horizontal axis shows the elapsed days ranging from the first nesting day to the seventh day after the last nesting. The open symbols in each figure indicate the concentration at the time of egg laying and the blackened ones show the concentration of the seventh day after nesting.

3.2.1. Blood Protein. TP and ALB of each female decreased gradually as nesting times increased. Moreover, the concentration at the egg laying showed higher value than the one on the seventh day after each egg laying (Figures 8 and 9). 


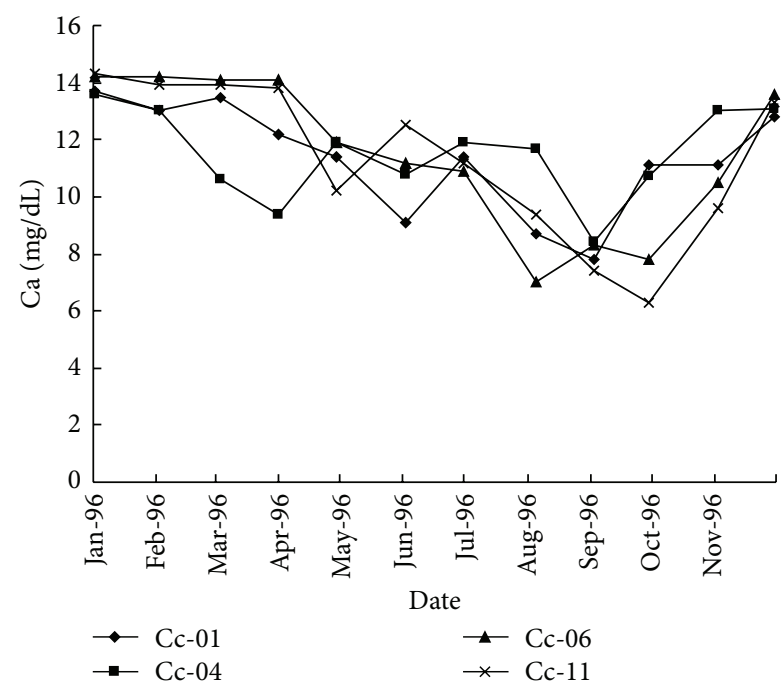

Figure 5: Change in plasma Ca concentration of breeding female loggerhead turtles (Cc-01, Cc-04, Cc-06, and Cc-11).

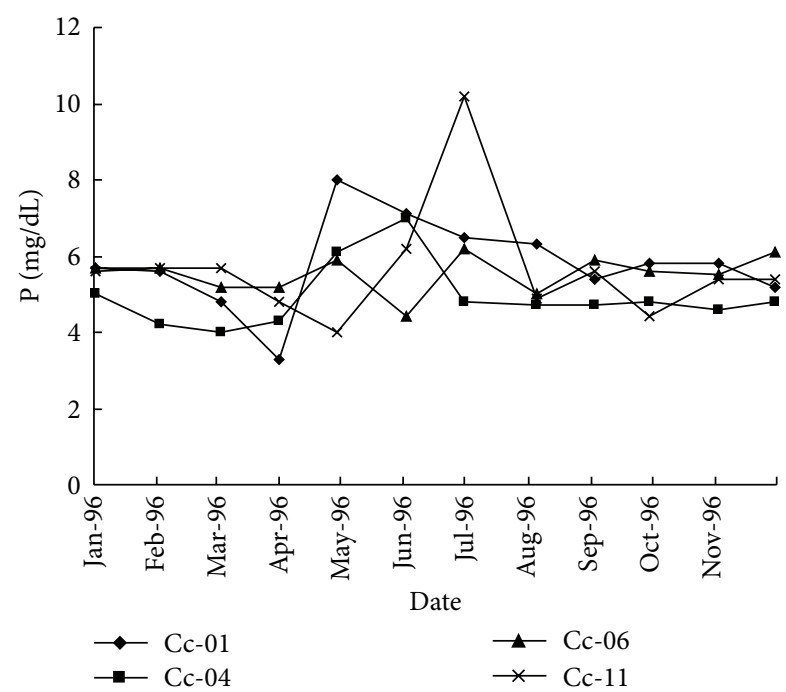

FIGURE 6: Change in plasma $\mathrm{P}$ concentration of breeding female loggerhead turtles (Cc-01, Cc-04, Cc-06, and Cc-11).

3.2.2. Blood Lipid. TG of each female decreased gradually as nesting times increased in the same manner as blood protein did. However, TG changed inversely to protein showing that the concentration at the egg laying to be lower than the one on the seventh day after each egg laying (Figure 10).

About TCHO, there was the concentration difference among individuals as observed in the annual examination. As was expected, TCHO of Cc-11 indicated remarkably high value in comparison to the other 3 turtles (Cc-01, 04, and 06). Moreover, TCHO of Cc-11 at egg laying indicated obviously higher values than those of the one on the seventh day after each egg laying. The other three showed almost constant values during nesting period (Figure 11).

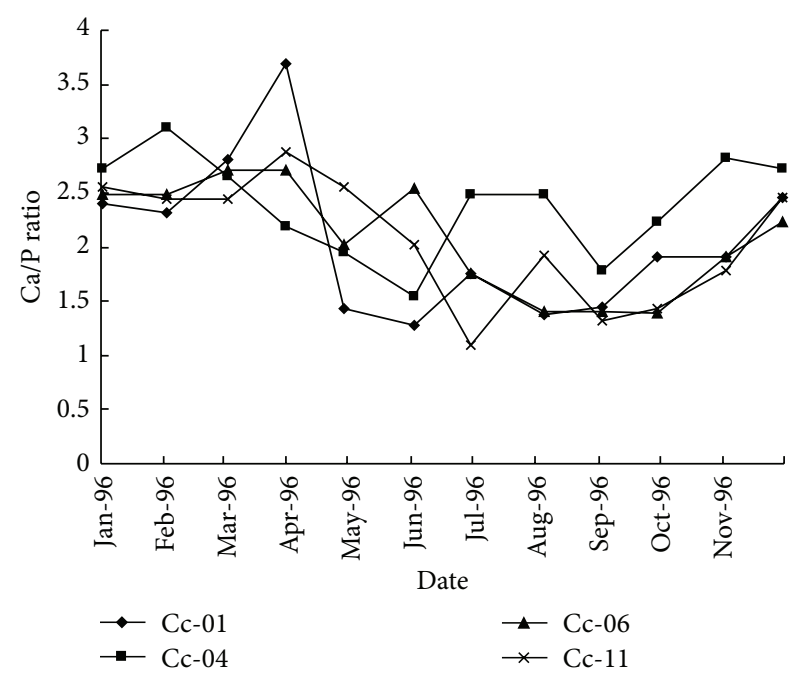

FIgURE 7: Ca/P value change in breeding female loggerhead turtles (Cc-01, Cc-04, Cc-06, and Cc-11).

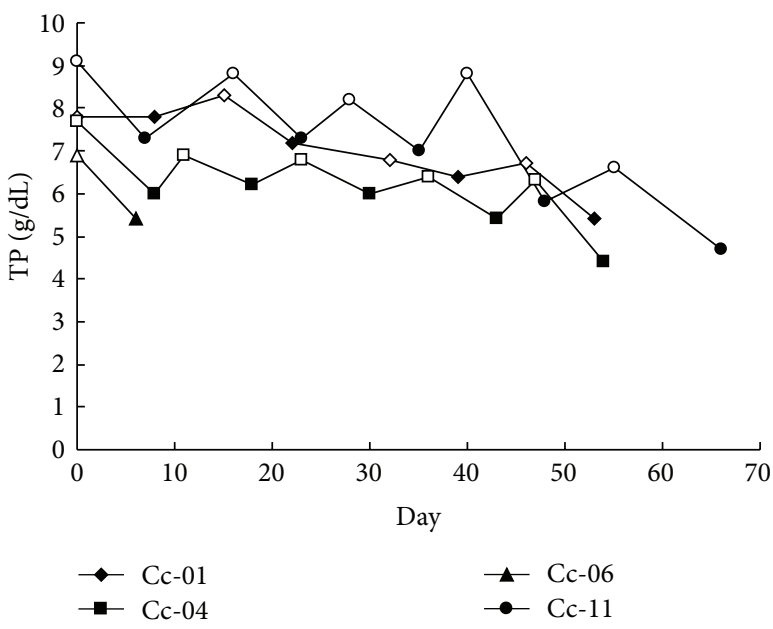

Figure 8: Change in plasma TP concentration of breeding female loggerhead turtles (Cc-01, Cc-04, Cc-06, and Cc-11) during the nesting period in 1996. Open symbols on the lines indicate the nesting day.

3.2.3. Blood Electrolytes. Both $\mathrm{Ca}$ and $\mathrm{P}$ at the egg laying showed higher values than the ones on the seventh day after each egg laying (Figures 12 and 13). Especially, P showed prominently that trend where the concentration at the time of egg laying could indicate more than four times higher than the one on the seventh day after each egg laying (Figure 13). When their concentration was considered as the ratio of $\mathrm{Ca} / \mathrm{P}$, it changed drastically from one to more than five between the time of egg laying and the seventh day after that. In the first half of nesting period, that trend was shown strongly, but in the last half of nesting period, the range of change became less (Figure 14). 


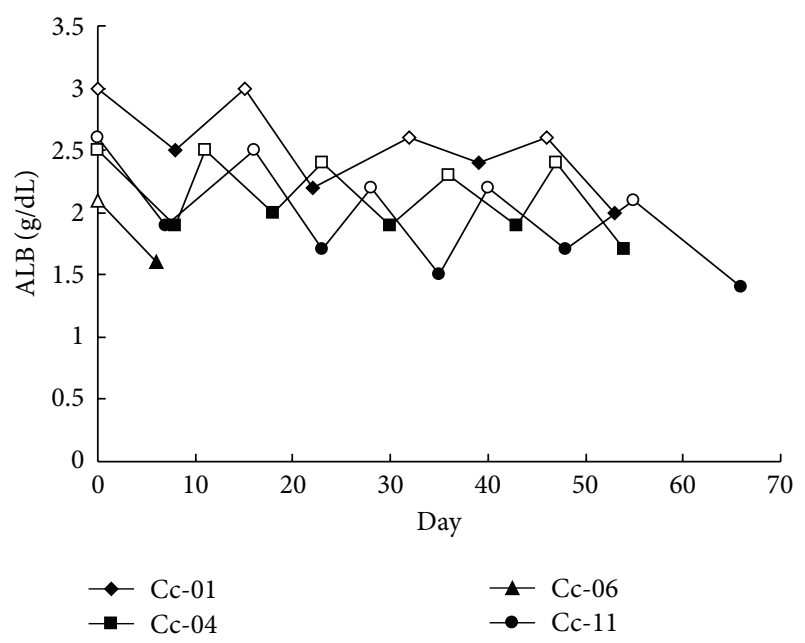

Figure 9: Change in plasma ALB concentration of breeding female loggerhead turtles (Cc-01, Cc-04, Cc-06, and Cc-11) during the nesting period in 1996. Open symbols on the lines indicate the nesting day.

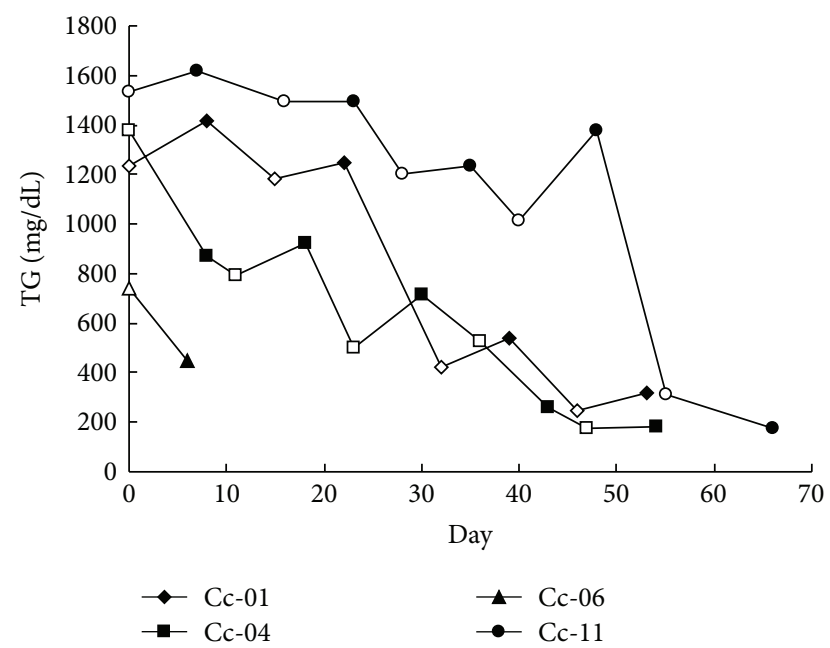

Figure 10: Change in plasma TG concentration of breeding female loggerhead turtles (Cc-01, Cc-04, Cc-06, and Cc-11) during the nesting period in 1996. Open symbols on the lines indicate the nesting day.

\section{Discussion}

In this study, Male's $\mathrm{T}$ increased during winter. For reptiles, there are several reports that show that testis started to develop during the low water temperature period [2-5]. So, it is assumed that the loggerhead turtles would indicate the similar pattern to the reported species.

On terrestrial reptiles, it is reported that male's TP and TG increase in relation to their reproductive season [6]. However, the significantly seasonal changes were not recognized in this study. It was considered that since the number of data in this study is limited to only two, significant changes were not appeared. About females, TP, TG, and TCHO need nutrition for the follicle developments, and these seasonal

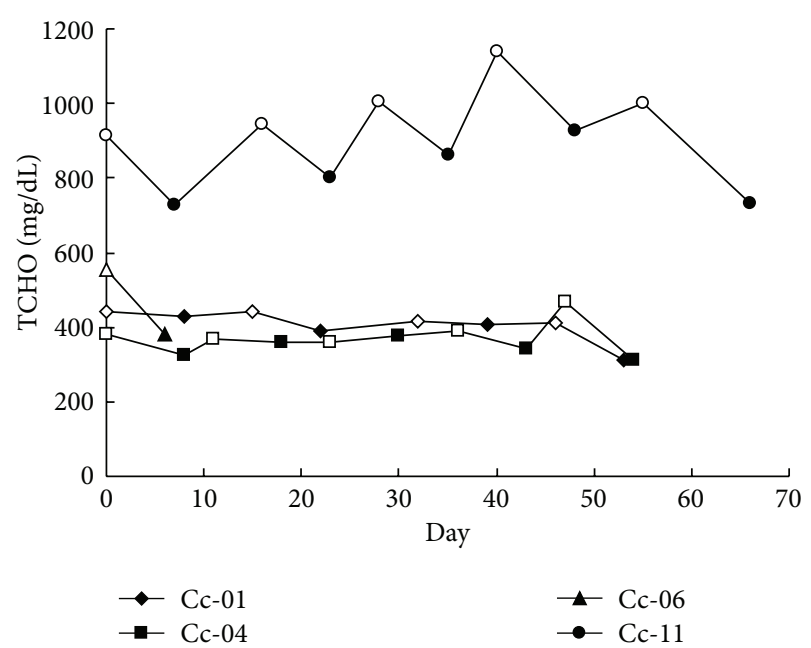

FIGURE 11: Change in plasma TCHO concentration of breeding female loggerhead turtles (Cc-01, Cc-04, Cc-06, and Cc-11) during the nesting period in 1996. Open symbols on the lines indicate the nesting day.

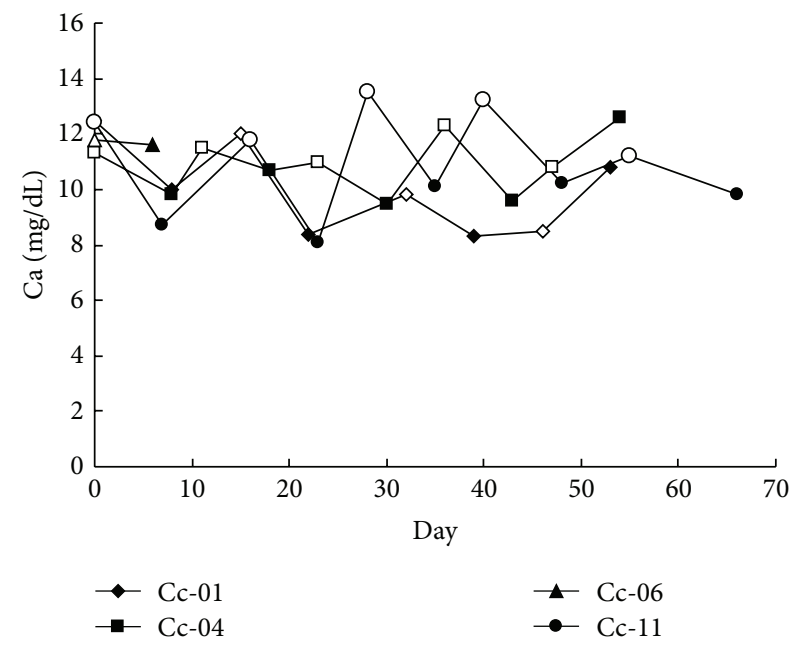

FIGURE 12: Change in plasma Ca concentration of breeding female loggerhead turtles (Cc-01, Cc-04, Cc-06, and Cc-11) during the nesting period in 1996. Open symbols on the lines indicate the nesting day.

changes indicated that females started to prepare for the next nesting from the previous autumn. Moreover, the result of blood sampling showed that TG hematogenously migrated to follicles during nesting period. Therefore, it was indicated that the development of follicles was maintained during the nesting period. TCHO of Cc-11 showed extremely high value, but the reason was not clear in this study.

From the poultries studies, it was reported that blood calcium concentration increased before ovulated egg entered shell gland and that calcium concentration gradually decreased during shell formation and increased again several hours before oviposition [7, 8]. This shows that calcium is transitioned from medullary bone to oviduct 


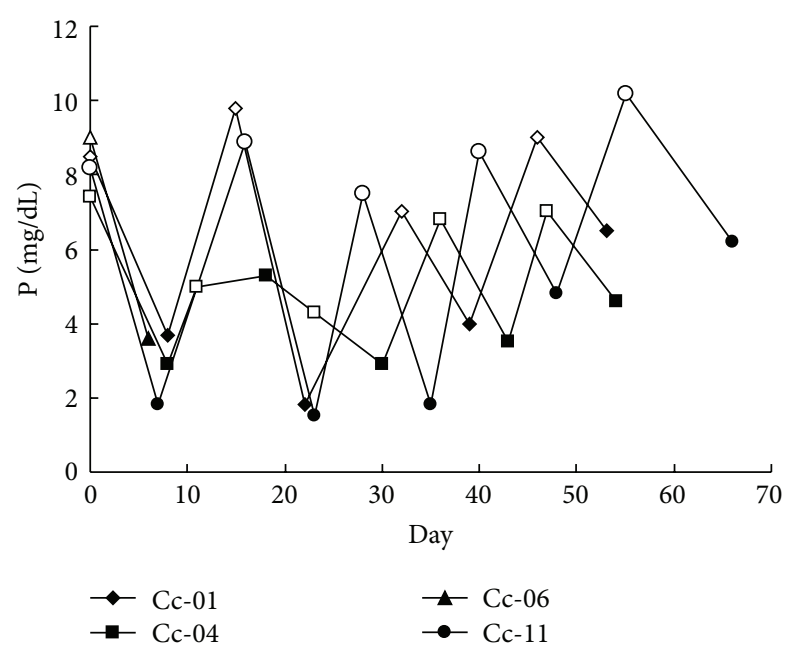

FIgure 13: Change in plasma $\mathrm{P}$ concentration of breeding female loggerhead turtles (Cc-01, Cc-04, Cc-06, and Cc-11) during the nesting period in 1996. Open symbols on the lines indicate the nesting day.

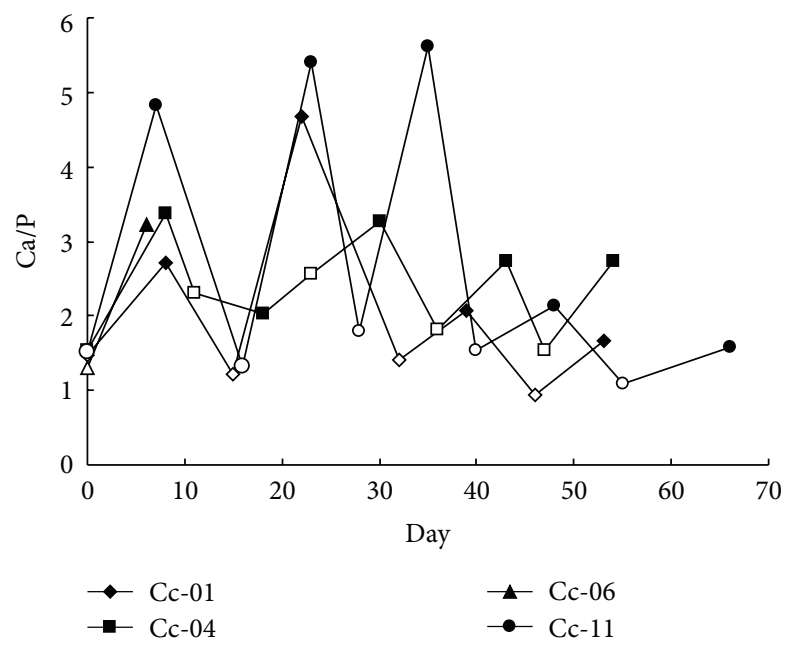

FIGURE 14: $\mathrm{Ca} / \mathrm{P}$ value change in breeding female loggerhead turtles (Cc-01, Cc-04, Cc-06, and Cc-11) during the nesting period in 1996. Open symbols on the lines indicate the nesting day.

hematogenously for the egg formation in the poultries. On the loggerhead sea turtles, it was also shown that $\mathrm{Ca}$ and $\mathrm{P}$ change dynamically during the period of one egg laying to another in this study. Both $\mathrm{Ca}$ and $\mathrm{P}$ indicated higher values in the egg laying time than those between egg layings. Moreover, considering ovulation is expected to occur within several days after egg laying based on progesterone concentration change; the preparation for the next egg formation has already started at the time of egg laying in sea turtles like the poultries [9]. Although the ratio of $\mathrm{Ca} / \mathrm{P}$ indicated the extremely high value on the seventh day after each egg laying, it is considered that eggs go into shell gland and their egg formation is undertaken actively at this time.
In the result of $\mathrm{Ca}$ and $\mathrm{P}$, it is shown that $\mathrm{P}$ made a strong contribution to the egg formation for loggerhead turtles as it does in the poultries. It is considered that $\mathrm{P}$ has a major role in the effective transition of $\mathrm{Ca}$ to shell gland. In the female, the ratio of $\mathrm{Ca} / \mathrm{P}$ was higher after summer. It was thought that it was caused by the effective accumulation of $\mathrm{Ca}$ which was to be used in the next nesting period. In the annual observation of $\mathrm{Ca}$ and the ratio of $\mathrm{Ca} / \mathrm{P}$, it was found that they increased from previous autumn as estradiol [9], TP, and lipids did. Therefore, it shows that females prepare Ca along with TP and lipids for half a year for the next egg laying.

In other sea turtles, Kemp's ridley (Lepidochelys kempii), it was reported that $\mathrm{Ca}$ increased in winter [10]. But the relation to $\mathrm{P}$ was unknown. In this study, it becomes clear that $\mathrm{Ca}$ was flowed at the egg laying and the ratio of $\mathrm{Ca} / \mathrm{P}$ was important factor as well. In this paper, plasma $\mathrm{Ca}$ was measured as total calcium; yet, if ionized calcium and protein-binding calcium are separately measured aftertime, it is considered that understanding on the detailed involvement of $\mathrm{Ca}$ in the egg laying will deepen.

In the previous studies, it is considered that sea turtles have no medullary bones. However, plasma P indicated large swings in the egg laying in this study. So, this indicates the possibility that sea turtles store $\mathrm{Ca}$ in their bones, not in medullary bone cavity, and that they have it transitionally hematogenously at the time of egg laying. This result is very interesting in understanding the mechanism of storing $\mathrm{Ca}$ and egg formation that coincide with egg laying.

In addition, for the healthy reproduction of sea turtles, the content of $\mathrm{Ca}$ and $\mathrm{P}$ in their food needs to be focused on and not only the amount of $\mathrm{Ca}$ intake but also of $\mathrm{P}$ and their balance should be paid attention to.

Most of the information of sea turtles, especially of loggerhead turtles has been given from wild individuals [11]. The research using the same individual in the wild is extremely hard; therefore, the only way possible to know reproductive physiology was through analogy by putting together separate pieces of data obtained from separate individuals. However, this study was conducted under the completely artificial environment, and, moreover, the same individuals were studied over the long period. So the results show the essence of the reproductive physiology of loggerhead turtles. These data contribute significantly to not only resolution of unknown reproductive physiology of loggerhead turtles but also the conservation programs of endangered species in artificial environment.

\section{Disclosure}

None of the authors get any financial gain from corporations mentioned.

\section{Acknowledgments}

The authors would like to express special thanks to the late Dr. Takashi Sasaki for his stimulating discussions and critical reading of this paper. The authors are grateful to 
Dr. Mamoru Doi and all the staff at the Port of Nagoya Public Aquarium for their encouragement and cooperation.

\section{References}

[1] I. Uchida, "Indoor breeding of loggerhead sea turtles," Animal and Zoos, vol. 48, pp. 120-124, 1996.

[2] T. Joanen and L. McNease, "Reproductive biology of the American alligator in southwest Louisiana," in Reproductive Biology and Diseases of Captive Reptile, J. B. Murphy and J. T. Collins, Eds., vol. 1 of SSAR Contributions to Herpetology, pp. 153-159, 1980.

[3] V. Lance, "Reproductive in the alligator," in Proceedings of the 9th International Symposium on Comparative Endocrinology, Hong Kong, China., 1983.

[4] V. Lance, "Endocrinology of reproductive in male reptiles," in The Structure, Development and Evolution of Reptiles, M. W. J. Ferguson, Ed., pp. 357-383, Academic Press, London, UK, 1984.

[5] P. L. Risley, "The spermatogenic and seasonal cycle of the testis of the musk turtle, Sternotherus odoratus (latreille)," The Anatomical Record, vol. 57, article 78, 1933.

[6] B. Morpurgo and A. Gelman, "The effect of age, sex and diet on the plasma cholesterol levels of the Nile crocodile, Crocodylus niloticus," Comparative Biochemistry and Physiology A, vol. 99, no. 4, pp. 687-689, 1991.

[7] R. D. Hodges, " $\mathrm{pH}$ and mineral ion levels in the blood of the laying hen (Gallus domesticus) in relation to egg shell formation," Comparative Biochemistry And Physiology, vol. 28, no. 3, pp. 1243-1257, 1969.

[8] Y. Nys, T. M. N'Guyen, J. Williams, and R. J. Etches, "Blood levels of ionized calcium, inorganic phosphorus, 1,25dihydroxycholecalciferol and gonadal hormones in hens laying hard-shelled or shell-less eggs," Journal of Endocrinology, vol. 111, no. 1, pp. 151-157, 1986.

[9] Y. Kakizoe, M. Fujiwara, Y. Akune, Y. Kanou, T. Saito, and I. Uchida, "Cyclical changes of plasma sex steroids in captive breeding loggerhead turtles (Caretta caretta)," Journal of Zoo and Wildlife Medicine, vol. 41, no. 4, pp. 643-648, 2010.

[10] D. C. Rostal, D. W. Owens, J. S. Grumbles, D. S. MacKenzie, and M. S. Amoss, "Seasonal reproductive cycle of the Kemp's ridley sea turtle (Lepidochelys kempi)," General and Comparative Endocrinology, vol. 109, no. 2, pp. 232-243, 1998.

[11] C. J. Limpus, P. J. Couper, and M. A. Read, "The loggerhead turtle, Caretta caretta, in Queensland: population structure in a warm temperate feeding area," Memoirs, vol. 37, no. 1, pp. 195204, 1994. 

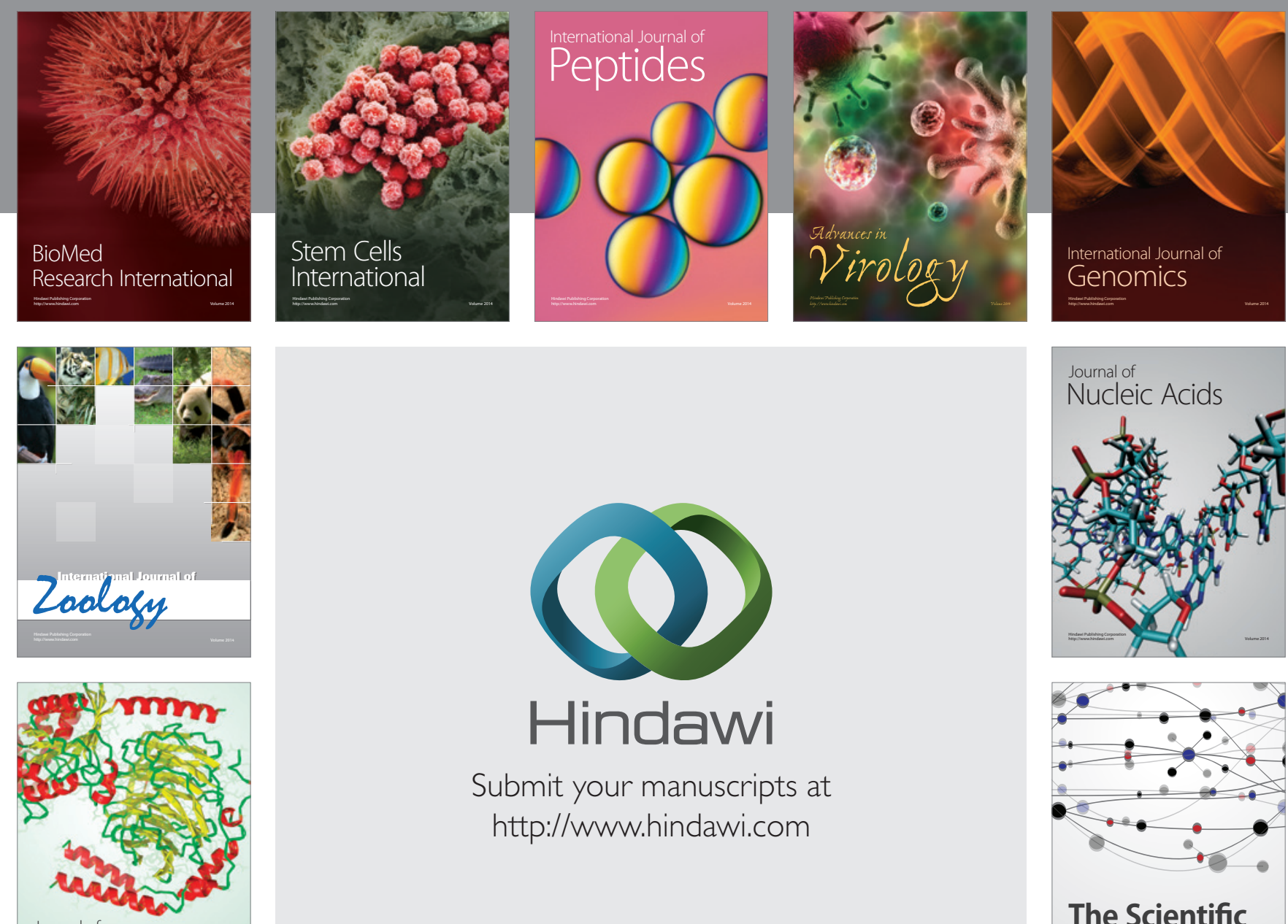

Submit your manuscripts at

http://www.hindawi.com

Journal of
Signal Transduction
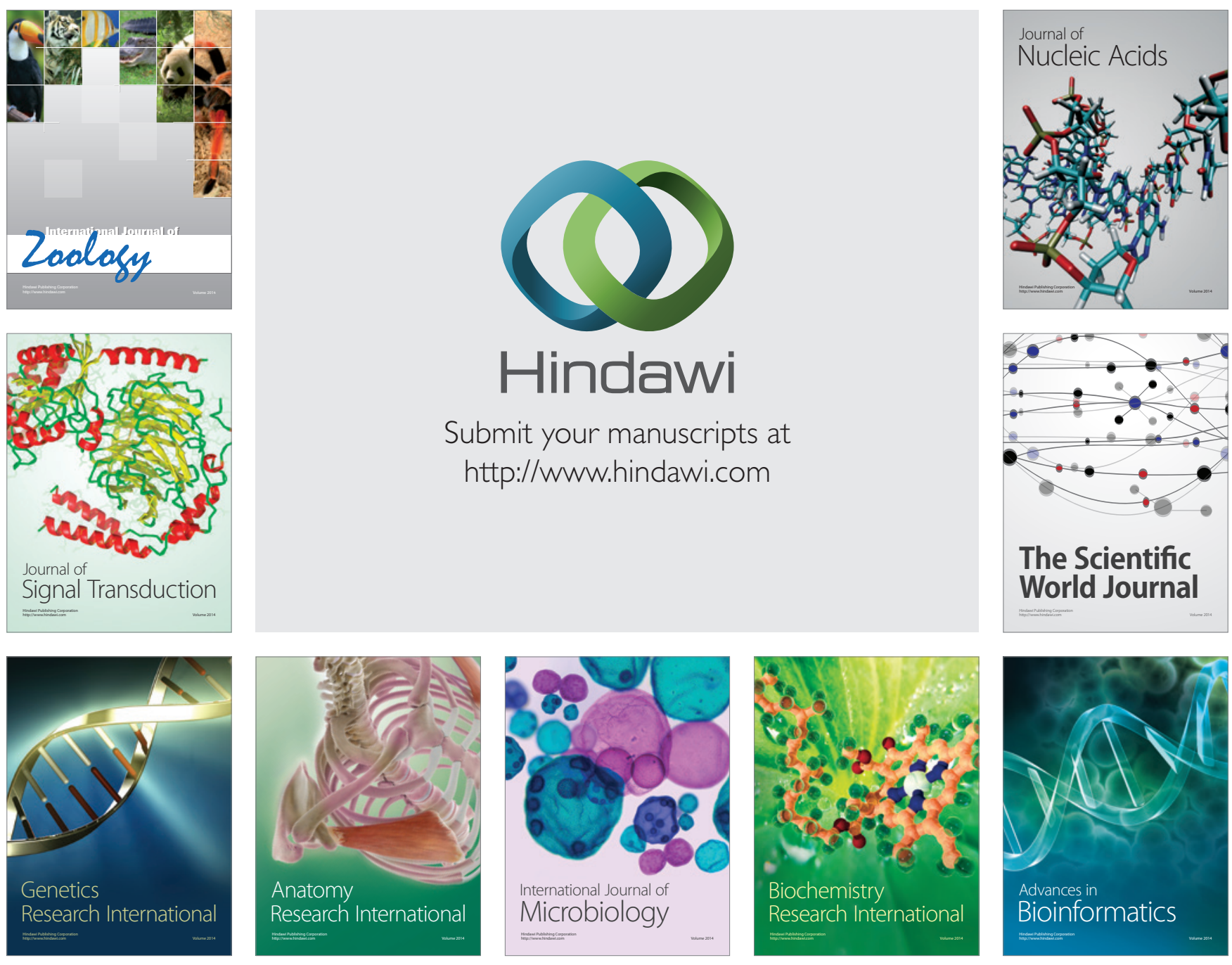

The Scientific World Journal
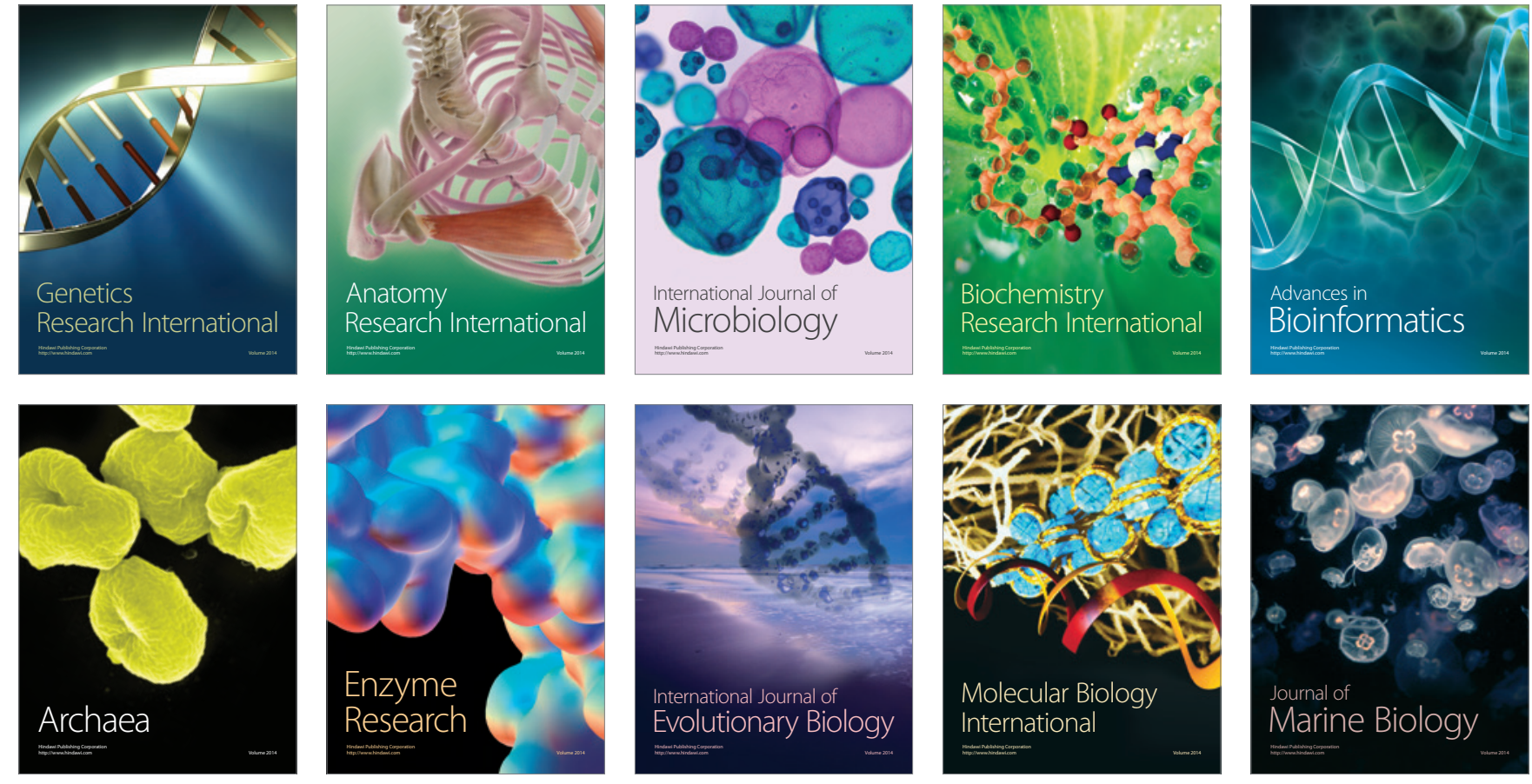